\title{
Stress measurement at loaded aluminium welds using diffraction methods
}

\author{
Michael Workowski ${ }^{\mathrm{a}}$, Thomas Nitschke-Pagel ${ }^{\mathrm{b}}$ and Klaus Dilger ${ }^{\mathrm{c}}$ \\ Technische Universität Braunschweig, Institute of Joining and Welding, Langer Kamp 8, \\ 38106 Braunschweig, Germany \\ am.workowski@tu-braunschweig.de,bt.pagel@tu-braunschweig.de, ck.dilger@tu-braunschweig.de
}

Keywords: aluminium, welded joints, deformation behaviour, FWHM, synchrotron radiation, neutron radiation

\begin{abstract}
Aluminium alloys welded with arc welding and electron beam welding processes were investigated to analyse the local deformation behaviour under static loads. Therefore strain measurements were carried out. These investigations were combined with X-ray diffraction experiments which should provide information about the residual stress condition and additionally about load-induced changes of the hardening condition. Additionally diffraction experiments using synchrotron and neutron radiation where carried out to analyse the deformation behaviour of particular welds under varying static loads.
\end{abstract}

\section{Introduction}

Due to their favourable mechanical properties in combination with low specific weight aluminium alloys, cold-formed and precipitation-hardened, are of great interest in the automotive and aircraft industries. Welding such materials leads to a local annealing process in heated zones around the welds. By this local heating the microstructure may be changed strongly, which results in inhomogeneous recrystallisation processes and at least in a strong loss of the initial mechanical properties. Depending on the width of the heated zone significant softening occurs in the weld seam and the adjacent heat-affected zones. The material properties vary locally. The softened zones may act like structural notches. In combination with geometrical notches and residual stresses the softened zones are preferential sites for the crack initiation under loading. Different welding processes, such as metal arc welding, tungsten inert gas welding or beam welding processes, generate rather different softening zones. So the structural notches are of great importance for the structural strength of the welded joints. To compensate the detrimental effect of these inhomogeneities completely only heat treatment of the joint can be used. Local post-weld treatments, for instance peening processes are not suitable to improve the fatigue strength of welds.

\section{Background}

In addition to defects and notches, variations of the microstructure are created during the welding process by the applied heat treatment. These inhomogeneities can be summarised under the terms of geometrical and metallurgical notches. In conjunction with tensile residual stresses both types of notches could reduce the life cycle of the welded specimen.

The influence of geometrical notches, residual stresses and different types of finishing was often an object of research. Concerning the influence of the metallurgical notch there are only a few studies published [1;3]. Primarily the lifetime of welded specimens depend on the shape of the weld toe notch. Stress concentrations and strain constraints at the notch root cause a multi-axial stress condition. Plastification will be constrained and the specimen will collapse prematurely. Tensile residual stresses additionally can play a significant role in the premature collapse of welded samples. If the summation of tensile residual stresses and load stresses exceeds the yield strength of the material, the plastic deformations activate fatigue of the welded joint. 
The term "metallurgical notch" refers to the abrupt changing of mechanical properties in the environment of the weld seam as a result of the applied heat treatment $[1 ; 2]$. In practical use, this distribution of mechanical properties can create complex strain and stress conditions. However, a quantitative assessment of the metallurgical notch is very difficult. Especially the separation from other effects, e. g. the influence of the geometrical notch or the influence of residual stresses, is hardly possible. Most of the published experiments reveal that the effect of the geometrical notches is mostly the dominating factor with regard to the lifetime of the welds. Exceptions are welded joints of precipitation-hardened aluminium alloys. If the welding process causes a wide heataffected zone of softening, the failure location shifts from the weld toe to the softening zone [3]. In the case of the heat input being much more focused, softening zones next to the weld seam can appear. In an image of the metallurgical cross-section these zones are not detectable. Only by using fine-scaled hardening measurements the softened areas can be visualised.

\section{Proceeding}

The aim of the present studies is the localization of occurring strains under static loading. Therefore two aluminium alloys, the precipitation-hardened aluminium alloy AlSi1MgMn (EN AW 6082 - T6) and the naturally hard aluminium alloy AlMg3 (EN AW 5754 - H22), are investigated. The influence of varying heat input was investigated by using two different welding processes, such as the gas tungsten arc (GTA) and the gas metal arc (GMA) process.

For a better understanding of the strain distribution, tension tests with transient deformation measurements using an optical 3D deformation measuring system based on gray-scale pattern recognition were done. In this measurement method a stochastic pattern with black spots on a white background was printed on the surface of the specimens. By means of two special cameras the displacements of typical spots are observed during loading. This allows the calculation and the planar visualization of the local strain distribution.

Diffraction experiments were used to determine load-induced changes of the residual stress states. The changes of the stress states may allow findings about the inhomogeneous deformation behaviour of the loaded samples. XRD analyses were carried out after defined load steps to obtain knowledge concerning the relationship between residual stresses, characteristic microstructure and the occurring strains under loading. Therefore the $\{511 / 333\}$ patterns of the aluminium matrix were measured by means of $\mathrm{CuK} \alpha$ radiation using a middle point free 7 axis diffractometer. To calculate the FWHM values of the measured diffraction lines the Rachinger correction and the Lorentzian peak fit was applied.

Further diffraction experiments using synchrotron radiation were carried out to analyse the deformation behaviour under varying static loadings. Therefore welded samples were loaded incrementally by a testing machine located in the beamline. By means of the diffraction experiments in a transmission arrangement the elastic strains over thickness were measured and converted into stress states. The experimental station is operated in the energy-dispersive mode of diffraction. These investigations were performed at the experimental station EDDI (Energy Dispersive Diffraction) of the electron storage ring BESSY II in Berlin, which is operated by the HelmholtzZentrum Berlin (HZB).

At the research reactor BER II, also operated by the HZB, experiments using neutron diffraction were done to determine the over-depth stress distribution. Samples preloaded to different levels were analyzed and compared. That way the change of the over-depth stress state caused by the plastic deformation was investigated.

\section{Observation and Results}

In the first step micrographs of the welds were characterized. In addition to investigations of the microstructure, hardness measurements were carried out. Figure 1 shows the measured Vickers hardness distribution using the Ultrasonic Contact Impedance method (UCI). For the aluminium 
alloy EN AW 6082 a significant softening beside the weld seam was found, which is caused by the dissolution of precipitates as a result of the annealing. These softening zones are characteristic for precipitation-hardened aluminium alloys like EN AW 6082. Naturally hard aluminium alloys show wide softening next to the weld only due to the dissolution of surface hardening.
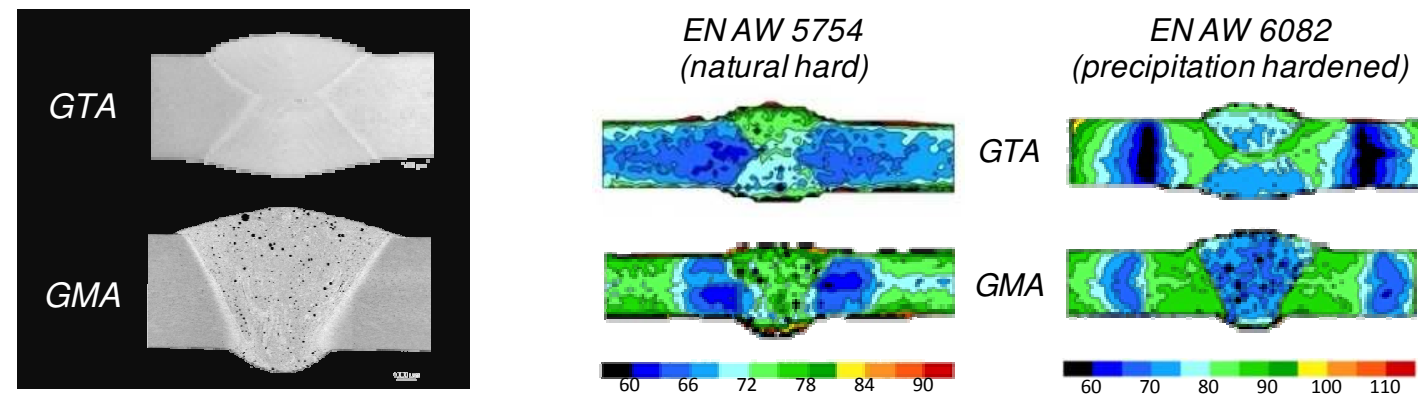

Figure 1: Micrograph and hardness measurements in welded conditions using the UCI method

During the tensile tests the occurring displacements were measured using an optical measurement system. Figure 2 shows the strain distribution through the cross-section on a load level near tensile strength, calculated on that basis. It is obvious that the welded precipitation-hardened alloy primary expands in the heat-affected zone in a short distance to the weld toe. In the base material fewer strains were measured. Both, for GTA and GMA welds, a very similar distribution can be seen. For the naturally hard alloy a distinction must be made between the weld types. While the GTA welds expand primarily in the base material away from the weld seam, the highest strains at GMA welds were detected in areas which were affected by the welding process. In this case the base material plays a minor role. Summarizing a good correlation between the hardness distribution and the strain occurring under loading can be seen for both aluminium alloys.
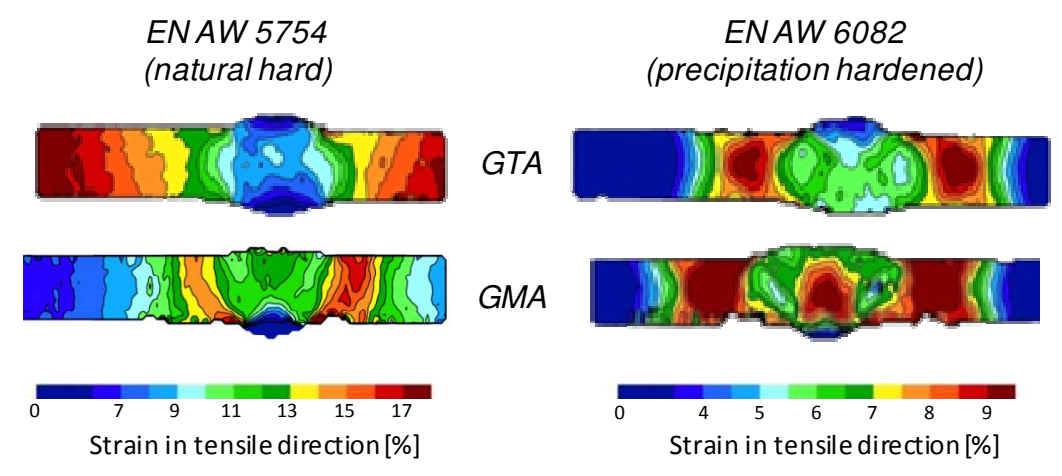

Figure 2: Strain distribution under tensile loading

Figure 3 shows a comparison of the transverse residual stresses measured along a path perpendicular to the welding direction on the surface of the samples. On different load levels the transverse residual stresses as well as the full width at half maximum (FWHM) were determined for GTA and GMA welds of both aluminium alloys.

In as-welded conditions only low residual stress was measured in the heat-affected zones. The maximum value of the residual stresses in that area is less than $40 \mathrm{MPa}$ for all of the investigated welding types. Near the weld toe very slight compressive stresses were measured. At a distance of a few millimetres the stresses rise to tensile range. Nonetheless, it can be assumed that the samples are nearly free from residual stresses in the welding conditions.

In Figure 3 it can be seen that the stress distribution is affected by the plastic deformation. A loading to tensile strength leads to a decrease of the residual stresses in the heat-affected zone. After loading only compressive stresses were measured at welded samples made of EN AW 5754. At the alloy EN AW 6082 also a decrease is detected. But in this case the stresses only change in an area near the weld toe. At a distance of approximately 6 to $8 \mathrm{~mm}$ the stresses remain stable. This nonuniform change of the residual stress state indicates the inhomogeneous deformation behaviour of those samples. 

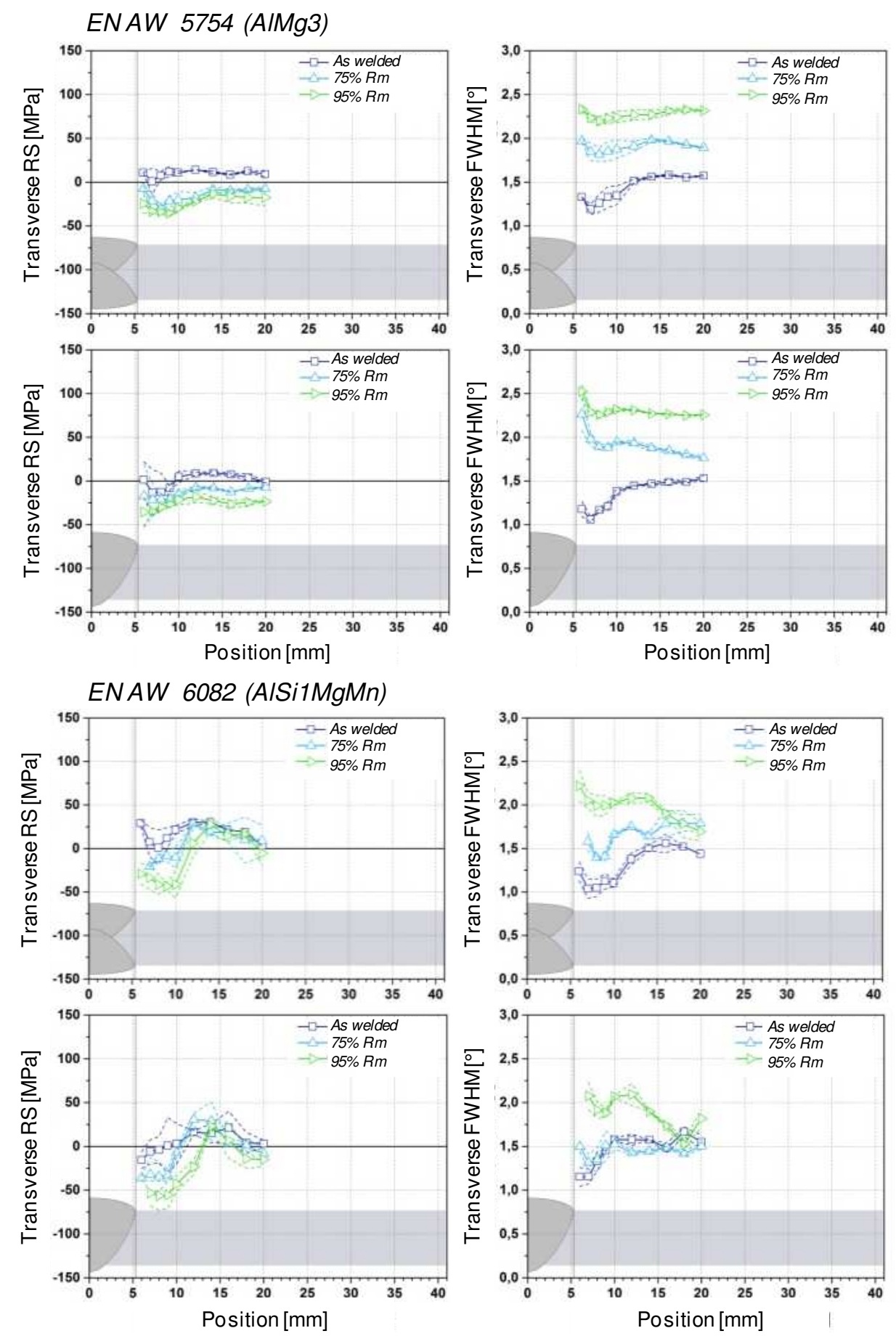

Figure 3: Measuring of the surface transverse residual stresses using XRD (top: GTA, bottom: GMA welds)

This can also be shown by analysing the FWHM of the diffraction lines which is related to the present crystallographic defects. Across the heat-affected zones of samples made of EN AW 5754 the loading leads to a constant rise of the FWHM. For the welded samples made of EN AW 6082 it is obvious that the loading has less effect on the area at least as far as $10 \mathrm{~mm}$ beside the weld toe. In the area next to the weld seam the FWHM increases significantly. For both tested load levels the maximum increase was detected a few millimetres adjacent to the weld toe. The longitudinal residual stress distributions shown in Figure 4 confirm these findings. 

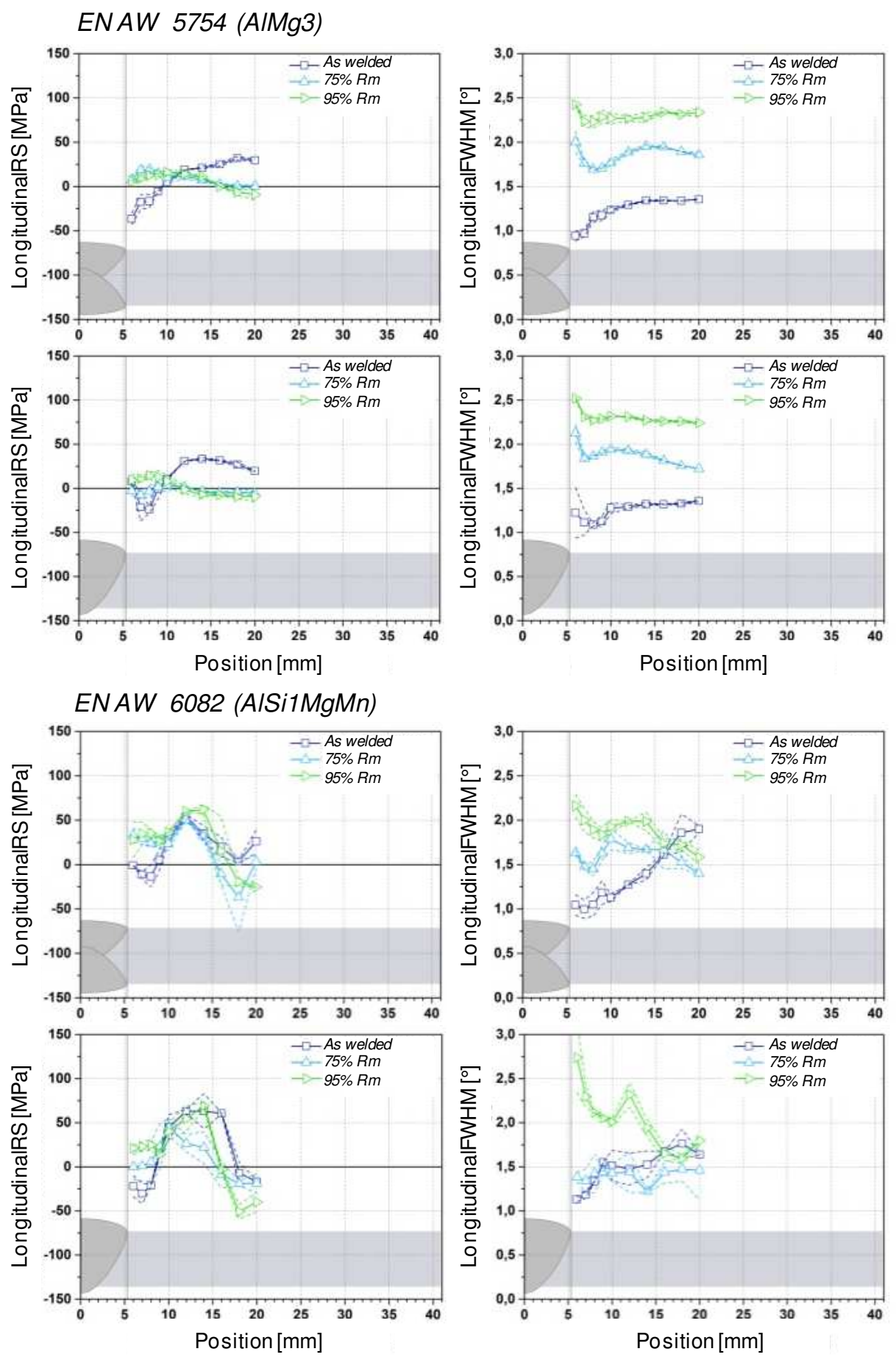

Figure 4: Measuring of the surface longitudinal residual stresses using XRD (top: GTA, bottom: GMA welds)

Additional synchrotron radiation was used to measure the residual stresses over sheet thickness along a path perpendicular to the welding direction. By means of that measurement method the load-induced elastic strains were determined and converted into stresses. The measurements were carried out on flush grinded GTA welds made of EN AW 6082. The samples were incrementally loaded by means of a testing machine, which was installed in the beamline. That means that in-situ measurements were carried out under tensile and compressive loading. 

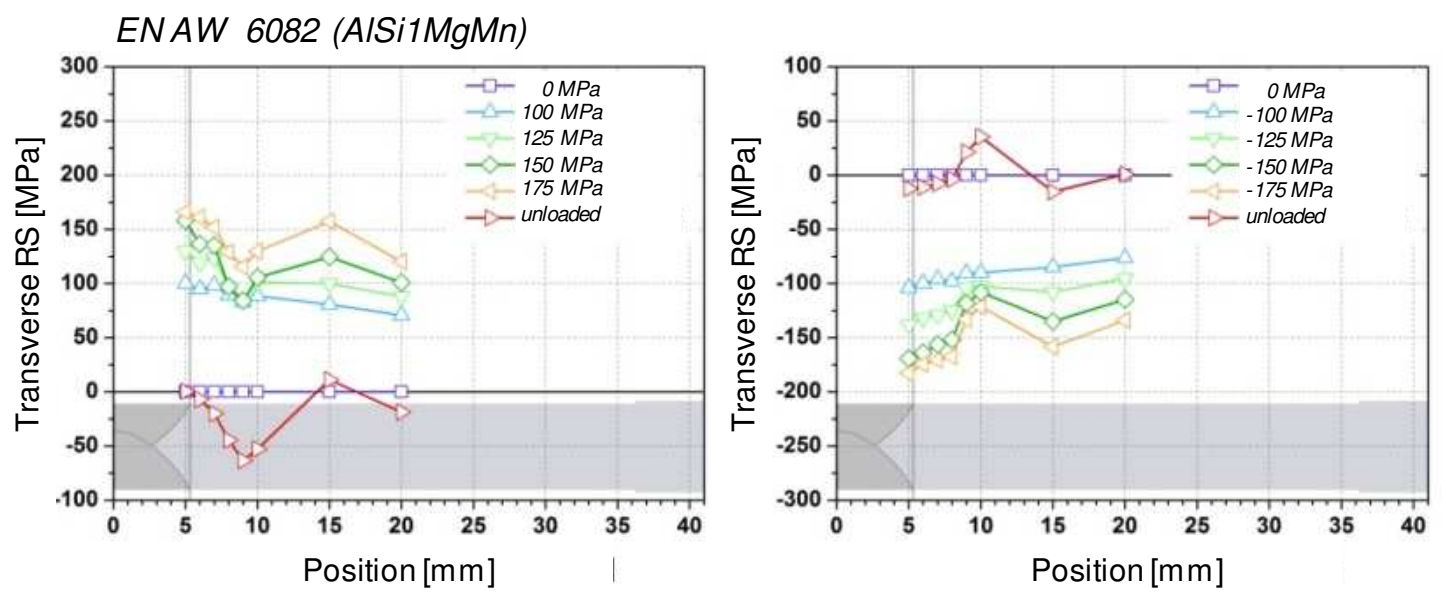

Figure 5: Measuring of load-induced stresses using synchrotron radiation; left: tensile loading; right: compressive loading

Figure 5 shows the stress distributions referring to the initial state. Both, tensile and compressive loading to $100 \mathrm{MPa}$ leads to a constant stress level in the heat-affected zone. A further increase of the load influences the shape of the measured distributions. In an area in close vicinity to the weld the calculated stresses remain nearly stable. A significant drop is seen. On the highest tested load level the stresses in the heat-affected zones are clearly lower than at the weld toe or in the base material. After unloading stresses remain in the heat-affected zone. In the case of tensile loading residual stresses of $70 \mathrm{MPa}$ were determined at a distance of approximately $4 \mathrm{~mm}$ to the weld toe after unloading. After compressive loading $40 \mathrm{MPa}$ remain in that area. This shows the change of the residual stress state caused by the deformation.

Diffraction experiments using neutron radiation were used for the over-depth determination of the stress distribution. For GTA- and GMA-welded samples made of the alloys EN AW 5754 and EN AW 6082 the determined transverse residual stress distributions in loading direction are shown in Figure 6. The distributions before loading are compared with those after loading with $95 \%$ of the tensile strength.
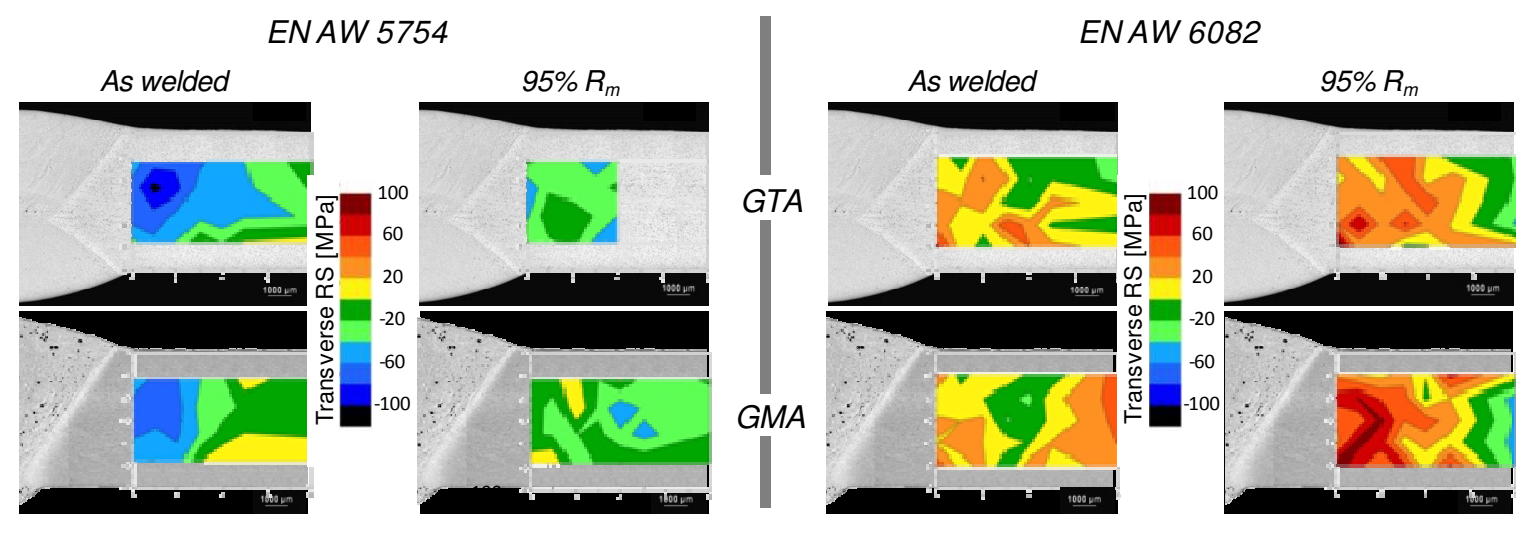

Figure 6: Measuring of the over-depth transverse residual stresses using neutron radiation

In the heat-affected zones of EN AW 6082 the transverse residual stress state changes by the applied load. Mainly in the centre of the plate at a distance of approximately $4 \mathrm{~mm}$ to the weld toe the stresses increase. Before loading residual stresses of small amounts near zero were detected in the heat-affected zones. By loading the transverse residual stresses rose to $60-80 \mathrm{MPa}$ in these areas. This applies in equal measure to both arc welding methods.

For the naturally hard alloy EN AW 5754 an increase of the transverse residual stresses can also be observed in the heat-affected zones of both arc welds. In the initial state compressive residual stresses are located in the heat-affected zones. By means of tensile loading these compressive stresses degraded slightly. In the heat-affected zones stresses near zero were measured after loading at $95 \%$ of the tensile strength. However, the difference between the initial and the loaded states are significantly lower than in the case of the EN AW 6082. 

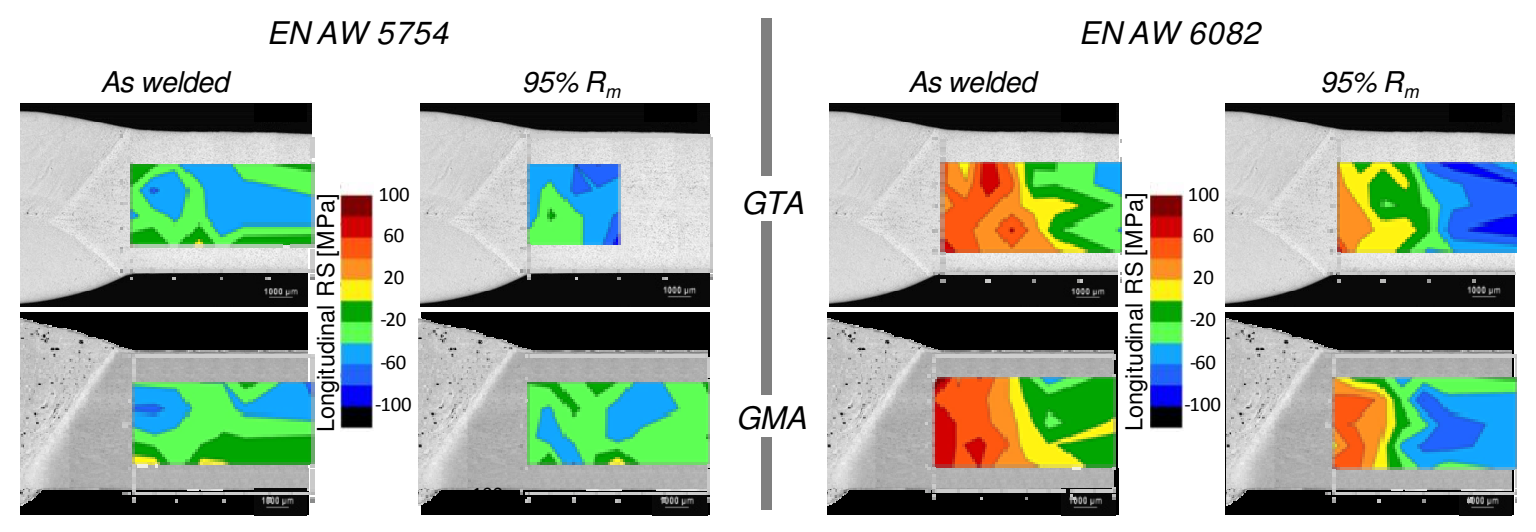

Figure 7: Measuring of the over-depth longitudinal residual stresses using neutron radiation

Figure 7 shows the distributions of the longitudinal residual stresses, which were also affected by the deformation. While only slight changes in the naturally hard alloy can be seen, the residual stress states in the heat-affected zones of the alloy EN AW 6082 change more markedly. In that areas the tensile residual stresses degrade. Compressive residual stresses were built up.

\section{Discussion and Conclusions}

In this study two different aluminium alloys were investigated with regard to their strain distribution and the resulting variations of the residual stress state under static load. The characterization of the welded specimen showed clear differences between the aluminium alloys.

Similarly to the hardness, the measured strain distributions differ among the investigated aluminium alloys. While the strain behaviour of the precipitation-hardened alloy EN AW 6082 is clearly influenced by the welding process, the GTA welds made of EN AW 5754 mainly expand in the base material far away from the weld seam. The welds made of the EN AW 6082 show a wide zone of high increased strain in the heat-affected zone. Considering the local hardness after welding these high strains were concentrated on the areas of softening.

The differing deformation behaviour can also be shown by the X-ray diffraction experiments. The surface residual stress state is influenced by loading. In the heat-affected zones of EN AW 6082 the residual stresses decrease locally, while the stresses in the base remain unchanged. In the case of the naturally hard alloy EN AW 5754 a constant decrease over the measuring path can be seen. The FWHM values of EN AW 5754 rise nearly constantly along the whole measuring path, too. However, almost no changes are detected in the base material of EN AW 6082. The changes of the FWHM values are located in the immediate neighbourhood of the weld. By taking the displacement measurements into account a good correlation between the FWHM changes and the occurring strains can be seen.

Diffraction experiments by means of synchrotron radiation indicate also inhomogeneous deformation behaviour of welded samples of EN AW 6082. With increasing load the welds show a clear drop of the measured stresses next to the weld. After unloading some stresses remain. This suggests to a local deformation of the samples in these areas.

The change of the residual stress distribution was also shown by over-depth measurements using neutron radiation. For EN AW 6082 tensile loading leads to a build-up of transverse residual stresses in the heat-affected zones. The longitudinal residual stresses decrease under loading.

\section{Acknowledgement}

The presented investigations were supported by the Deutsche Forschungsgemeinschaft (DFG) in the project Ni508/6-1 ,Inhomogenes Verformungsverhalten in Entfestigungszonen geschweißter hochfester Aluminiumwerkstoffe". The authors would like to express their thanks for the support. 
The in-situ stress measurements were carried out at the EDDI-Beamline (BESSY) of HelmholtzZentrum Berlin (HZB). The experiments using neutron diffraction were done at the research reactor BER II, also of Helmholtz-Zentrum Berlin. We would like to thank HZB for the allocation of synchrotron radiation beamtime.

\section{References}

[1] Hickel, H.; Wohlfahrt, H.; Macherauch, E.: Zum Dauerschwingverhalten elektronenstrahl- und WIG-geschweißter Bleche des martensitaushärtbaren Stahles X2 NiCoMo 188 5. DVSBerichte Bd. 26, Strahltechnik VI, 1973, pp. 53-56 (in German)

[2] Hickel, H.: Dissertation Universität Karlsruhe, 1973 (in German)

[3] Zinn, W.: Untersuchungen zum Dauerschwingverhalten von Stumpfschweißverbindungen aus den naturharten Aluminiumlegierungen $\mathrm{AlMg} 3$ und $\mathrm{AlMg} 4.5 \mathrm{Mn}$. Deutscher Verlag für Schweißtechnik, Düsseldorf, 1990 (in German) 